\title{
Moçambique 41 anos Depois: 'Crónica' de uma Imaturidade Política
}

\author{
Mozambique 41 years later: \\ 'Chronicle' of a Political Immaturity \\ Mozambique 41 años después: \\ 'Crónica' de una Política de inmadurez
}

Sheila Khan*

\begin{abstract}
Resumo: O presente ensaio procura pensar Moçambique nos 41 anos da sua independência. Fruto de uma hegemonia política personificada pela FRELIMO, Moçambique vive hoje o assombro das hostilidades militares com a RENAMO. Num jogo inoperativo de negociações e mediações, a maturidade que outrora se celebrou caiu perante uma realidade desassossegada com questões relacionadas com corrupção, dívidas ocultas e uma grande resistência de, efetivamente, se aceitar a democracia.
\end{abstract}

Palavras-chave: independência; maturidade; FRELIMO; RENAMO

Abstract: This essay reflects on Mozambique in the 41 years of its independence. Fruit of the political hegemony personified by FRELIMO, Mozambique now experiences the wonder of military hostilities with RENAMO. In an inoperative game of negotiations and mediations, the maturity that once took place fell before a restless reality with issues related to corruption, hidden debts and a high resistance to, effectively, accept democracy.

Keywords: independence; maturity; FRELIMO; RENAMO

Resumen: En este ensayo se piensa Mozambique en los 41 años de su independencia. Fruto de la hegemonía política personificada por el FRELIMO, Mozambique ahora experimenta la maravilla de las hostilidades militares con la RENAMO. En un juego que no funcionan negociaciones y mediaciones, la madurez que se llevó a cabo una vez cayó ante una realidad inquieta con temas relacionados con la corrupción, deudas ocultas y una alta resistencia, con eficacia, a aceptar la democracia.

Palabras clave: independencia; madurez; FRELIMO; RENAMO

\footnotetext{
* Investigadora do Centro Interdisciplinar de Ciências Sociais da Universidade do Minho (CICS. NOVA.UMinho).<sheilakhan31@gmail.com> < dados biográficos/biographic data>
} 


\section{Introdução}

Em 1964, no seu primeiro livro de poemas, Xigubo, o poeta moçambicano José Craveirinha escreve com uma clarividência assombrosa: "Poema do futuro cidadão":

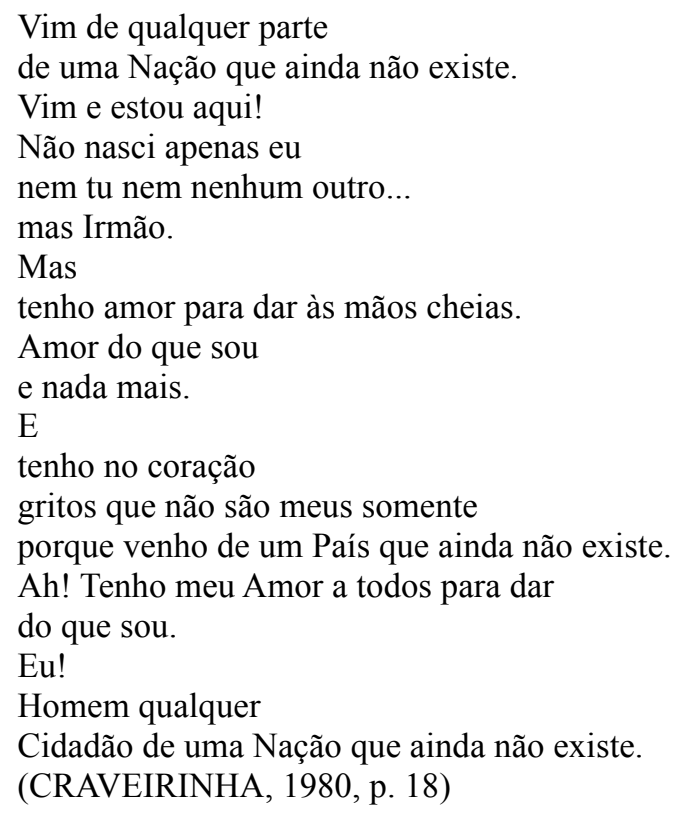

Este poema simboliza manifestamente uma reivindicação subjetiva, datada de um tempo árduo, autoritário com os 'Outros' colonizados, em que o poder colonial despia estes da sua dignidade humana e da soberania política. Mas é também um poema que sinaliza um tempo que, a acontecer de acordo com a vontade do poeta, seria feito de fraternidade, de igualdade e de comunhão. Uma simples pergunta: depois de 41 anos de independência é ainda este o poema que Moçambique personifica, nos tempos atuais, depois da sua luta de libertação nacional e após o Acordo Geral da Paz ${ }^{1}$ (AGP) assinado a 4 de Outubro de 1992 na cidade de Roma? A resposta é simplesmente não.

A evocação poética para abrir este ensaio tem uma intenção definida: a poesia moçambicana serviu como arma de confronto, de crítica e de

\footnotetext{
${ }^{1}$ O Acordo Geral da Paz (AGP), assinado na cidade de Roma a 4 de Outubro de 1992 entre a FRELIMO (Frente Nacional de Libertação de Moçambique) e a RENAMO sinalizou formalmente o fim da guerra civil que durou 16 anos (1976-1992).
} 
pensamento sobre o futuro de uma nação por “existir". Neste momento, esta nação encontra-se num caminho brutalmente inseguro, como se o poema na sua força, apresenta-se como uma epifania da qual ninguém pode desviar o olhar e desfocar a perspetiva de um país que se traiu a si mesmo. Jorge Rebelo, um dos grandes ideólogos da FRELIMO, numa entrevista dada ao Jornal Savana, questiona-se sem pudor nem medo, se quem traiu a nação não foram aqueles que por ela lutaram. Na leitura de Jorge Rebelo sobre a situação económica debilitada de Moçambique, junta-se o estilhaçar e a mutilação ideológica de muitas ilusões relativas às personalidades que fizeram da FRELIMO um arauto de liberdade, emancipação política, económica e social do seu povo, ao sopesar nas seguintes palavras o estado da nação. A partir da governação do anterior presidente da República de Moçambique, Armando Quebuza, e do escândalo desvendado recentemente sobre as dívidas ocultas, resultado de empréstimos privados em prol de interesses aquém da economia do país, pergunta:

Um fenómeno que me deixa intrigado: como foi possível que um camarada, que deu provas de nacionalismo e patriotismo, a certa altura se deixe dominar pela ganância e desgrace o seu país? Estes apetites já existiam nele quando se engajou na luta, ou surgiram mais tarde? Não sei a resposta. Mas em certa medida nós próprios somos responsáveis, por não termos reagido quando começámos a detetar esses comportamentos (REBELO, 2016, p. 27).

Uma negativa redonda para esta nação que hoje se desconhece mesmo entre aqueles que lutaram pela sua independência. Pensar sobre os 41 anos pós-independência e fazer a partir destes uma avaliação objetiva mereceria um maior distanciamento da situação atual por que está a passar Moçambique: a tensão político-militar entre FRELIMO ${ }^{2}$ e RENAMO ${ }^{3}$ desde a tomada de posse do seu atual presidente da república, Filipe Nyusi (15 de Janeiro de 2015), no contexto da qual a RENAMO reivindica, ao longo de um atual processo de negociações e de mediações, em primeiro lugar, a legitimação da sua vitória em seis províncias; em segundo, a revisão constitucional e que muito tem sido contestada e revogada pela FRELIMO; em terceiro, a integração nas forças de Defesa e de Segurança dos militares da RENAMO; e, em último lugar, a consequente descentralização administrativa do

\footnotetext{
2 Frente Nacional de Libertação de Moçambique.
}

3 Resistência Nacional Moçambicana. 
poder. Acrescem a esta paisagem descompassada em termos políticos, a descida da cotação das matérias-primas como o carvão e o gás natural; a criminalidade galopante e mais, recentemente, a revelação insultuosa de uma dívida oriunda de empréstimos não revelados durante a governação do anterior presidente Armando Guebuza (2005-2015).

Por uma questão de organização deste ensaio e para conceder uma melhor compreensão analítica para aqueles que desconhecem esta realidade, optei por recorrer a recortes de jornais moçambicanos, a entrevistas realizadas a personalidades moçambicanas para colocar o leitor no contexto desta reflexão sobre os 41 anos decorridos sobre a independência de Moçambique.

\section{Ilhas de Utopia: A Geração do Homem Novo}

Por mais que o povo olhe para este presente com um esgar de angústia e de deceção, todos aqueles que sentiram e testemunharam o momento da independência de Moçambique (25 de Junho, 1975), sabem que esse foi a nota mais sublime de uma pauta que foi celebrada e glorificada nos vários discursos de Samora Machel, que assumiu a presidência da FRELIMO após a morte de Eduardo Mondlane em 1969, tornando-se presidente da República de Moçambique entre 1975 até à sua morte a 19 de Outubro de 1986:

A primeira palavra que lhes queremos transmitir é uma palavra de tranquilidade e de confiança. A FRELIMO nunca lutou contra o Povo Português ou contra a raça branca. A FRELIMO é a organização de todos os moçambicanos sem distinções de raça, de cor, de etnia ou de religião. A nossa luta sempre se dirigiu contra o sistema colonial de opressão e de exploração [...] não há raças superiores nem inferiores. Mas não basta falar em harmonia social para que de um dia para o outro todos se entendam. O convívio que é necessário estabelecer deve ser um convívio pleno, a todas as horas, e não somente o convívio superficial das horas de emprego e das relações profissionais. Em particular os clubes e associações baseados na origem étnica, e regional devem transformar-se em associações de todos os moçambicanos, em centros da cultura moçambicana (MACHEL, 1974, p.8, 17-18).

Moçambicanas, moçambicanos, operários, camponeses, combatentes, povo moçambicano, em vosso nome às zero horas de hoje, 25 de Junho de 1975, o Comité Central da FRELIMO proclama solenemente a independência total e completa de Moçambique (extrato do Discurso de Samora Machel no dia 25 de Junho de 1975). 
Todos os que viveram debaixo dos seus pés a euforia de uma terra livre e soberana e que sonharam com novos ventos de progresso e de desenvolvimento para um país cuja população era, na sua maioria, iliterata - um país à deriva económica e socialmente, após a fuga dos chamados 'retornados' e portugueses (KHAN, 2009) - acolheram com grande esperança a Revolução Moçambicana construída pela FRELIMO e pela visão carismática de Samora Machel. Ainda corriam os ventos e vozes da independência e já a FRELIMO se confrontava com problemas urgentes que requeriam atenção e soluções concretas: a) o desenvolvimento da unificação nacional e a mobilização política das massas populares; b) a reconstrução e reestruturação económica; c) a autoridade nacional e popular representada pela FRELIMO e pelos seus comités partidários, que asseguravam os princípios da 'Disciplina, Ordem e Consciência Política', numa sociedade que precisava de se estruturar segundo uma nova ordem política, moral e social; uma sociedade a que era necessário retirar todos os vícios e caprichos da herança colonial; d) a consciência política versus estratificação, o regionalismo e o tribalismo, com o intuito de criar um sentido de coesão nacional, sem interferências regionais, étnicas e tribais.

Como outras ex-colónias portuguesas, Moçambique depara-se já no início da sua nova caminhada com verdadeiras deficiências criadas e deixadas pelo ex-colonizador: uma iliteracia esmagadora; pobreza; desconhecimento dos processos democráticos; divergências raciais e étnicas (que, ainda hoje perduram, não obstante os esforços de combater e de anular estas mesmas diferenças); obscurantismo, amplamente, arreigado a práticas e crenças deslocadas de uma visão educativa e de uma educação cristã socialmente aceitáveis, que muitas vezes, descambava para uma obsessiva busca de tradições étnicas; uma pesada herança colonial na persistente burocracia. Poucos anos antes de 75, num documento intitulado 'FRELIMO - Segunda Década, Novos Combates' com a data de 1972, é bem saliente a consciência que a FRELIMO detinha sobre a necessidade de construção de uma nova sociedade moçambicana, cuja base teria de ser totalmente diferente das estruturas sociais, administrativas, burocráticas, económicas deixadas pelos portugueses. Além desta constatação, desenhava-se para esta força de libertação nacional a premência da emergência de uma nova sociedade, cuja organização, manutenção e durabilidade teria de se sustentar numa nova e vigorosa conceção ontológica e cultural de novos homens e mulheres africanos. 
No que concerne à nova sociedade moçambicana pareceu, desde logo, inevitável e essencial à FRELIMO a formulação de uma premissa: que o poder popular fosse a sua força central. Assim, e a título de exemplo do cumprimento desta sua intenção, a FRELIMO refutou veementemente a existência da propriedade privada e, como alternativa, o partido propôs que o poder popular deveria ser a base fundamental da nova ordem social. Após a independência, em 1977, em Novembro e durante a visita de quatro dias à Nigéria, o presidente Samora Machel fez o discurso, do qual retiro este pequeno excerto:

Que tipo de sociedade construir? Novos elementos, que se propõe substituir os exploradores que fugiram, apareceram na sociedade moçambicana, tentando restabelecer, em novas formas, a exploração capitalista praticada pelos portugueses. Foi verdadeiramente este $o$ objetivo da nossa luta? A resposta das massas foi clara: rejeitar qualquer restauração da exploração capitalista. Eles afirmaram que lutavam pela libertação total e não para substituírem um explorador por outro. (AGÊNCIA DE INFORMAÇÃO DE MOÇAMBIQUE, 1977, p.17)

Com a inflexão ideológico-política socialista em 1977, com um pendor marxista-leninista, e com a FRELIMO já transformada em partido político, Moçambique sofre uma remodelação económica e social e organizativa significativa, desde os grupos dinamizadores (que até 1978 se dividiam entre Grupos dinamizadores de local de trabalho e Grupos Dinamizadores de local de residência, após o que, em 1978, apareceriam os Grupos de Vigilância e, nos anos oitenta, os Comités Sindicais), passando pelas aldeias comunais e os tão inglórios e polémicos campos de reeducação ${ }^{4}$. Foram, sem dúvida, durante a governação de Samora Machel, anos de grande austeridade social e

\footnotetext{
${ }^{4}$ A título informativo, os campos de reeducação assumiram-se como local de punição para comportamentos dos cidadãos que eram tidos como não normativos, fora dos costumes e princípios definidos pela FRELIMO. Estes campos de reeducação foram criados no contexto da chamada 'Revolução Moçambicana', o que a meu ver, alcança uma semântica de paradoxos na própria historiografia da FRELIMO: libertar o povo do colonialismo para, depois, enclausurar perante uma austeridade moral quase totalitária. Sobre os campos de reeducação ver no registo ficcional, algumas contribuições relevantes para melhor se compreender os estigmas, o sentido de ostracização, de desconhecimento e de iniquidade associadas à existência dos campos de reeducação. Dessas contribuições ressalvo o romance do historiador e escritor João Paulo Borges Coelho que em Campo de Trânsito (2007), embora a nível ficcional, retrata rudeza e a precariedade existencial intrínsecas na experiência neles vivida. A nível do trabalho de investigação registo dois trabalhos: de Nazir Can, 'Para Além da História: Campo de Trânsito de João Paulo Borges Coelho' (2009) e de Sheila Khan 'Narrativas, rostos e manifestações do pós-colonialismo moçambicano nos romances de João Paulo Borges Coelho’ (2008).
} 
política, uma atenção quase obsessiva perante tentativas de sabotagem económica e mesmo societal. Importa fazer aqui uma pausa: este é um período em que Moçambique procura com todos os meios possíveis ajudar o ANC (Congresso Nacional Africano) e, ao mesmo tempo, tem de pugnar com duas frentes fortíssimas, colocadas mesmo junto à sua fronteira: por um lado, a África do Sul com o seu sistema de Apartheid e, por outro lado, o governo racista da Rodésia do Sul, atual Zimbabué. Foi um tempo, como confessa o poeta moçambicano Luís Carlos Patraquim, em que "as pessoas falavam sobretudo no nós colectivo..." (LABAN, 1998, p.940). Essa força da coletividade estava bem presente também na organização e logística das chamadas aldeias comunais ${ }^{5}$, uma estratégia que a FRELIMO incentivou e implementou no país de modo a revitalizar a sua economia e, paralelamente, educar o povo para uma consciência política de união e de comunhão com a construção não apenas da Revolução Moçambican mas, também, do Homem Novo. Tendo por finalidade a formação de uma nova geração de homens e mulheres africanos, a FRELIMO incitou os povos moçambicanos a abraçarem um projeto social e cultural através de uma nova sociedade sem raças, tribos, e religiões, que podia ser estabelecida e florescer para benefício do poder das massas. Como documentado pelo jornal Revolução Moçambicana, já em 1974 (n.59, Abril-Junho), Samora Machel enfatizou repetidamente a relevância de a FRELIMO fazer do seu sustentáculo uma sociedade sem distinções, na qual todos os "moçambicanos de todas as raças e grupos étnicos, credos e backgrounds sociais, jovens e velhos, homens e mulheres exigem a independência nacional e identificam-se totalmente com os princípios e o programa da FRELIMO" (1974, p.20).

Como resultado destas diretrizes e premissas, o 'Homem Novo' (expressão que se estendia a homens, mulheres e crianças) tinha de se concentrar na construção de uma nova sociedade; no estabelecimento de novas relações sociais sob o manto da fraternidade e da igualdade;

\footnotetext{
${ }^{5}$ Luísa Diogo, ministra das Finanças entre 1999-2005, acumulando com este cargo o de primeiraministra desde 2004 até 2005 , observou no decurso de uma palestra dedicada ao "Pensamento de Samora Machel sobre o Desenvolvimento Económico de Moçambique": "Se formos a analisar as razões que ditaram a criação das aldeias comunais, muitas dessas razões foram prevalecentes, quando olhamos para as necessidades humanas, ao nível de professores, médicos e enfermeiros, vamos perceber que o acesso a esses serviços foi facilitado pelas aldeias comunais. Pensou-se que as pessoas estariam melhor, quando estivessem próximas, prefiro não discutir os rótulos, mas não há dúvidas que um agregado rural é mais acessível do que a dispersão rural.

Quando falamos das associações e das cooperativas, dos instrumentos de produção, entendemos que esses esquemas de organização são melhores, porque tudo que sejam desafios de gestão, contabilidade e decisões técnicas, funciona melhor em cooperativa". (SAVANA, entrevista a Luísa Digo, 2016, p. 3)
} 
na libertação do espiríto capitalista; na orientação para o coletivismo; na consciência das capacidades advindas da força popular; e, finalmente, num conhecimento não baseado nas tradições arcaicas, no obscurantismo e na superstição. Num tempo de grande mobilização nacional da FRELIMO, a educação foi, sem dúvida, uma ferramenta e um trunfo imprescindível, desenhando-se como uma declaração do pilar na luta pela consolidação nacional moçambicana. A partir deste focalização política, a FRELIMO entendeu que a educação podia (e devia) ser um símbolo da derrota e desmantelamento das prévias estruturas educacionais coloniais. Confrontada com a herança da mentalidade e dos valores colonialistas, a FRELIMO lança uma vasta campanha educativa, proclamando que a iliteracia devia ser erradicada e que a educação devia ser democratizada, de modo a garantir que o povo moçambicano, "de todas as raças e grupos étnicos, credos e backgrounds sociais, jovens e velhos, homens e mulheres" (REVOLUÇÃO MOÇAMBICANA, 1974, p.20), tivesse igual acesso à educação e ao desenvolvimento intelectual.

Numa entrevista a Michel Laban, no seu terceiro volume do seu livro Encontro com Escritores Moçambicanos, Ungulani Ba Ka Khosa, na altura um jovem engajado com a Revolução Moçambicana, relata os tempos desta força mobilizadora educativa na qual a FRELIMO, durante o governo de Samora Machel, implicou uma geração de futuros profissionais, a chamada "Geração 8 de Março", criada em 1977, cuja missão era "criar os alicerces da reconstrução de Moçambique após a independência. Para alguns, talvez muitos, foi um processo violento porque contrariava a sua vocação e anseios" (REBELO in SAVANA, 2016, p.4). Esta geração, como bem retrata Ba Ka Khosa, sacrificouse, em prol da sua 'submissão' que não tinha como alternativa senão respeitar as ordens da FRELIMO, às necessidades que o país exigia sem respeitar as subjetividades de cada um:

- Passou pelo Centro 8 de Março?

- Sim, nós é que abrimos - eu fui do primeiro grupo de 1977.

- Uma experiência interessante?

- A decisão presidencial foi a de 8 de Março de 1977, nós a 15 ou 20 de Março já estávamos cá. Viemos da Zambézia - da Zambézia éramos 57 -, depois fomos distribuídos por outros cursos; outros fizeram logo um curso intensivo de um ano, equivalente ao décimo primeiro, e como já estávamos no complementar, com um ano entraram logo na universidade. Outros como nós, e mais uns, foram para outros cursos. 
No Centro éramos cerca de duzentas pessoas, obviamente com muitas frustrações, porque muitos não queriam os cursos para que foram indigitados - eu, por exemplo, queria fazer Direito, mas não fiz porque na altura era a revolução.

- E quem decidiu que não podia seguir Direito?

- O próprio Ministério da Educação. Na entrevista disse: "Nós queremos tantos professores, há falta de professores. Tu vais tirar um curso de professor, vais ser professor. Mais tarde podes satisfazer a tua ambição ...”.

Todos nós sentimos uma frustração. Isso viu-se mesmo no Centro, sentiu-se isso. E também o próprio Centro trouxe-nos um esquema de militarização: tínhamos que rapar o cabelo como militares, aprendíamos a marcha militar - houve uma tentativa de militarização no sentido de nos impor uma disciplina. Tínhamos que andar fardados, se nos sentávamos num bar tínhamos que tirar o casquete - tudo na norma militar! Tínhamos mesmo instrutores militares. Portanto um centro de treino - para além das aulas. Era uma coisa caricata: os estudantes normais, que naquele ano ingressaram nos cursos da universidade, saíam das suas casas normalmente, e nós saíamos do Centro 8 de Março em grupos e a marchar em direção à faculdade! Entrávamos na sala, ficávamos de pé, o professor entrava, estávamos todos em sentido, sentávamonos! Tudo militarizado! (LABAN, 1998, p. 1048-49)

Estes foram os tempos de um carisma político, ideológico e social marcante. De tal maneira, que estes tempos representam uma linha de fronteira e de diferenciação que fixa a linha de engajamento político distintiva entre as várias gerações que Moçambique viu nascer e desenvolver ao longo dos seus 41 anos, e que Jorge Rebelo exprime na sua entrevista ao Jornal Savana, com as seguintes palavras:

- Desde a Independência nacional que o poder político está entregue à "geração da luta armada". Porém, de 2015 a esta parte, o poder foi transferido para a chamada "geração de 8 de Março". Que avaliação faz desta transição? Está a corresponder às expectativas? Os jovens estão a conseguir tomar conta do recado?

-A "geração do 8 de Março" cumpriu a missão que recebeu de Samora em 1977, a de criar alicerces da reconstrução de Moçambique após a independência. Para alguns, talvez muitos, foi um processo violento porque contrariava a sua vocação e anseios. Forçar alguém a aceitar ser professor quando o seu sonho era ser médico ou engenheiro não é fácil. Mas a maioria compreendeu e engajou-se nessa nova tarefa e 
fê-lo com alto sentido de responsabilidade e patriotismo. A "geração de 8 de Março" deu lugar a outra geração chamada da viragem, conforme proclamação do então Presidente Armando Guebuza em 2009. Esta é uma geração que está perdida porque ainda não sabe para onde virar-se. Não recebeu orientações do chefe que anunciou a sua criação, ele limitou-se a dizer que é a geração que luta contra a pobreza. Mas todas as chamadas gerações lutaram contra a pobreza (REBELO, 2016, p. 27).

Não obstante, todos os esforços da FRELIMO investidos na construção de uma nova nação moçambicana, a FRELIMO caiu num paradoxo perigoso e fatal: se, por um lado, Samora Machel reconheceu que a luta de libertação teria de ser uma causa abraçada de todos os "moçambicanos de todas as raças e grupos étnicos" (REVOLUÇÃO MOÇAMBICANA, 1974, p.20); por outro lado, ele próprio e sem rodeios declara "nós não reconhecemos tribos, raças ou credos". Christian Geffray, autor do livro La Cause des Armes au Mozambique: Anthropologie d'une guerre civile (1990), assinala que um dos fatores que sobreviveram e instigaram a guerra civil ou de desestabilização entre FRELIMO e RENAMO e que durou 16 anos (1976-1992, até ao Acordo de Paz, assinado a 4 de Outubro, de 1992), foi, declaradamente, o desrespeito da FRELIMO perante as tradições e autoridades étnicas e tribais. Uma guerra civil que devastou o país, nomeadamente, o Centro e Norte de Moçambique, legando uma herança de sangue, morte, destruição, fome e uma carnificina humana que, ainda hoje, não suscitou a nenhuma das forças intervenientes um discurso de reconciliação nacional, como testemunhamos em África do Sul e outros em países. Como bem observa Victor Igreja no seu ensaio 'Memories as Weapons', o silêncio sobre as memórias desta guerra é ainda denso e complexo: umas vezes, tais memórias são usadas como uma forma de pronunciamento da sua autoridade total por parte da FRELIMO; noutros momentos, são evocadas pela RENAMO como forma de contestar o multipartidarismo cínico e falso existente em Moçambique. E, nesse sentido, a manipulação em torno destas memórias e dos silêncios produzidos são bem visíveis quando, numa entrevista, Alice Mabota, Presidente da Liga dos Direitos Humanos, comenta: "what do you know about the sixteen years of war is that only one group killed, is this true? What are others doing?" (IGREJA, 2008, p. 543).

Com a assinatura do Acordo de Paz (1992), já com a presença de Joaquim Chissano, que sucedera a Samora Machel, após a morte deste a 19 de Outubro de 1986. É durante este percurso histórico que Moçambique 
testemunha a entrada do neo-liberalismo económico, o FMI, o Banco Mundial, e o multipartidarismo com as eleições democráticas de 1994, 1999, 2004, eleições ganhas por Joaquim Chissano que, por sua vez, será sucedido em 2005 por Armando Guebuza até 2015, sendo hoje a presidência da República de Moçambique ocupada por Filipe Nyusi.

Reconheço que uma análise mais decalcada que consolidasse a evolução social, económica e cultural fosse imprescindível. Contudo, uma análise assaz detalhada poderia ser um mergulho em águas profundas de uma reflexão que, assim, faria perder o sentido prático e diretivo deste trabalho sobre os 41 anos da independência de Moçambique. Por conseguinte, convido o leitor a um 'salto' até ao presente do contexto moçambicano, como forma de demonstrar, à luz da minha leitura dos acontecimentos que Moçambique experienciou - como se uma bipolaridade política se tratasse: por um lado, um tempo fértil de um carisma político e popular; e, por outro, o atual clima marcado por um fortíssimo desnorteamento. Desnorteamento gerado por um momento em que olhamos para os líderes políticos não como guardiões da nação e da sua segurança nacional, mas como 'traidores', corruptos, e desafiadores de um ideal que Samora Machel e a 'sua' Revolução Moçambicana quiseram construir: uma nação moçambicana una e soberana do Rovuma ao Maputo. Para um tempo em que, definitivamente, o conflito políticomilitar entre FRELIMO e RENAMO vai desafiar e desnudar a falácia que foi o Acordo de Paz de 1992.

\section{Moçambique: "Como foi possível...?": da Utopia à Desesperança}

No rescaldo final das eleições de 2014, Filipe Nyusi sai vitorioso das eleições com uma denúncia de fraude eleitoral por parte da RENAMO, maior partido da oposição, que reivindica a vitória em seis províncias (Sofala, Manica, Tete, Niassa, Nampula, Zambézia). Desde então, o país tem sido acometido por ataques quer de uma parte, quer de outra nas principais vias de circulação, em aldeias e povoações, acompanhados de fortes acusações de desestabilização e de culpabilização perante o impacto negativo e pernicioso quer para os investimentos externos quer para a circulação de pessoas e bens ao longo do país. A questão mais premente não gira em torno e apenas

\footnotetext{
${ }^{6}$ Pequeno recorte da entrevista realizada a um dos grandes pensadores e ideólogos da FRELIMO,
} Jorge Rebelo. Esta entrevista foi publicada pelo jornal Savana a 27 de Maio de 2016. 
da vitória fraudulenta que muitos apontam à FRELIMO, a ferida está na distribuição da riqueza, na impossibilidade sempre sublinhada, em termos de disputa política, da descentralização do poder e, também, da falta de inclusão e de integração do exército mobilizado e desmobilizado da RENAMO. Há pouco tempo, Michel Cahen destacou, numa interessante entrevista, a personalidade hegemónica da FRELIMO como um obstáculo à paz e um elemento motivador das hostilidades militares entre FRELIMO e RENAMO, ao enfatizar o seguinte:

Independente de a RENAMO ter ou não capacidade militar, não representa obstáculo à paz, porque o país tem um problema político e não militar. Os confrontos são apenas a expressão militar de um problema político. Se fosse permitido que se imaginasse que o Presidente da República pudesse ser da FRELIMO e os governadores provinciais de outros partidos e vice-versa; se fosse aceite que a unidade nacional não é necessariamente o mesmo que homogeneidade nacional; se a base social da RENAMO tivesse uma parte dos recursos a que se diz com direito, principalmente em relação aos recursos recentemente descobertos e se a situação social da maioria da população moçambicana melhorasse, aí, o problema seria facilmente resolvido. A força da RENAMO deseja ser socialmente integrada, ou no exército ou nas forças policiais. O país precisa de reformas políticas para acabar com a visão hegemónica da nação moçambicana (CAHEN, 2016, p. 16).

Os investidores exteriores não estão desatentos à exploração do gás natural e do carvão. No entanto, o ambiente de grande instabilidade política tem, progressivamente, afastado a vontade e a dinâmica destes investimentos. Após uma situação de vários anos de crescimento económico (mas não acompanhado por um verdadeiro desenvolvimento social), Moçambique tem de lidar com a desvalorização do metical face ao dólar, a queda dos preços do carvão e do gás, a ausência de uma verdadeira política sustentável da agricultura, que permitiria que Moçambique não tivesse de importar produtos básicos que poderia produzir nas suas terras. Lutando contra diversidades climatéricas em zonas áridas e noutras zonas destruídas pelas cheias, hoje, Moçambique é um país no limbo de um descarrilamento nacional.

Para 'infernizar' este cenário, recentemente, foram reveladas dívidas contraídas durante o governo de Armando Guebuza, que não foram orçamentadas pelo governo moçambicano, e, muito menos, delas se informou o FMI e o Banco Mundial. Sob a expressão de dívidas 
ocultas ou escondidas, créditos contraídos por empresas privadas, sob a alçada de um presidente que vinha da guerra pela libertação nacional, e, de acordo com várias informações bem precisas:

[...] nos últimos meses foram descobertos seis empréstimos previamente não revelados, totalizando 1.482 milhões de dólares. Acrescido a um dúbio empréstimo de 850 milhões de dólares a favor da $\mathrm{EMATUM}^{7}$, supostamente para a compra de uma frota de barcos para a pesca de de atum (que incluiu 500 milhões de dólares a aquisição de lanchas para a guarda costeira).

O endividamento atingiu o pico em 2013-2014, durante a reta final do mandato do Presidente Armando Guebuza. Tinha como base a previsão de que Moçambique iria muito rapidamente se tornar num grande exportador de gás. Os empréstimos a favor da EMATUM, da Proindicus (622 milhões de dólares) e MAM $^{8}$ (535 milhões de dólares) foram usados para a segurança marítima e logística para os projetos de gás através de empresas privadas ligadas aos serviços secretos do país (VINES, 2016, p. 5).

A empreitada das dívidas ocultas ainda está por resolver. No entanto, quer o FMI, quer os doadores - que beneficiam o Orçamento do Estado Moçambicano com uma fatia de $12 \%$, o que ronda os 467 milhões de dólares de apoio financeiro -, suspenderam o apoio que Moçambique tem recebido. A este cenário adicionamos a incapacidade que a FRELIMO tem demonstrado perante todo o processo de negociações com a RENAMO no que diz respeito ao processo de descentralização do poder, inclusão e governação das províncias. Neste momento, é possível testemunharmos os poucos avanços com a comissão mista e com os mediadores internacionais, onde se incluem a União Europeia, a Igreja Católica, Presidente do Botsuana Quett Masire, em representação da Fundação para a Liderança Global, com sede em Londres, um representante da Fundação Faith, dirigida pelo ex-primeiro-ministro britânico, Tony Blair, e um representante do Governo da África do Sul. Diariamente, chegam notícias de ataques perpetrados pela RENAMO, de hostilidades militares nas principais estradas do país. O mais grave de tudo é que a mediação internacional que deveria funcionar, tem sido de certa forma retardada e obstruída pela oposição silenciosa de muitos dirigentes da FRELIMO e, ainda agora, na comemoração

\footnotetext{
Empresa Moçambicana de Atum.
}

8 Mozambique Asset Management. 
do 7 de Setembro ${ }^{9}$ deste ano, a Associação dos Combatentes da Luta de Libertação Nacional (ACCLN), na voz do seu secretário-geral Fernando Faustino, fez uma declaração arrasadora e virulenta, como se pode observar:

Nós estamos cansados de sermos mortos como se fossemos galinhas, queremos armas, queremos ensinar o Dhlakama e a Renamo, camarada Presidente, este é o nosso pedido, estamos prontos para derrubarmos seja quem for (VOZ da AMÉRICA, 8 de Setembro, 2016).

Reagindo a esta declaração da ACCLN, António Muchanga, portavoz da RENAMO declarou nesse mesmo dia:

Ficou claramente demonstrado que as pessoas que incitam a violência em Moçambique são as pessoas da Frelimo, o senhor Faustino não só é secretário-geral da Associação dos Combatentes como também é marido da ministra da Administração Estatal, se for ver como é que os nossos membros são assassinados ao nível de base vai encontrar que nesses jogos estão envolvidos os secretários de bairros, administradores e governadores porque recebem essas aulas para perseguir e matar os membros da Renamo da ministra da Administração Estatal, esposa do senhor Faustino (VOZ da AMÉRICA, 8 de Setembro, 2016).

Muitos devem perguntar, que futuro para Moçambique? A resposta a esta interrogação não é fácil e não transporta consigo qualquer elemento que, nos próximos tempos, possam aplacar as preocupações e angústias de um povo e de uma 'nação' inoperante e incapaz de pelos seus meios apresentar uma solução válida e democraticamente aceitável. Na sua habitual crónica de opinião do jornal CanalMoz, o jornalista moçambicano Adelino Timóteo, escreve um dos textos mais contundentes ao chamar a Moçambique "O País do Nunca Mais":

O caminho mais rápido para se chegar ao País do Nunca Mais é a ausência da Paz. No País do Nunca Mais, a paisagem que nos mostram é que, enquanto uns minguam à água, comida, outros minguam de perderem a conta aos zeros da sua riqueza financeira. No País do Nunca Mais, a alta corrupção é apadrinhada pelo

${ }^{9}$ O 7 de Setembro ficou também conhecido como o Dia da Vitória. Neste dia foram assinados em Lusaka (Zâmbia) entre o Estado Português e a Frente Nacional de Libertação Nacional (FRELIMO), que definiram e consagraram a independência de Moçambique. 
Estado, e a prisão é medida compulsória para o pilha-galinhas. No País do Nunca Mais, a corrupção é legal. No País do Nunca Mais, os assassinatos de intelectuais e da massa pensante estão legalizados, por isso nunca há culpados nem suspeitos. No País do Nunca Mais, quanto mais a guerra, mais bem-estar daqueles que nunca produziram senão esquemas de a voltarem a reacender. No País do Nunca Mais, a morte de uns justifica o luxo de outros, os palacetes e os carros topo de gama. No País do Nunca Mais, há mais admiração pela obra dos criminosos de colarinho branco do que propriamente por aqueles que têm habilidade e talento de criar. No País do Nunca Mais, o sonho foi capturado, é propriedade de um punhado (TIMÓTEO, 2016, p. 3-4).

Não quer isto dizer, que a sociedade civil moçambicana esteja desatenta e desmotivada perante este cenário tão turbulento. Pelo contrário, vários organismos (Centro de Integridade Pública; Liga dos Direitos Humanos; Fundação Mecanismo de Apoio à Sociedade Civil, entre outros) têm vindo a tecer publicamente críticas sobre as divídas ocultas e o impasse nas negociações entre FRELIMO e RENAMO. No entanto, e num artigo de reflexão com uma lucidez exemplar, Noé Nhamtumbo, jornalista moçambicano, do jornal digital Canalmoz, escreve as palavras que desnudam, a meu ver, a personalidade social e política atualmente enraizada no país, no artigo de opiniãointitulado "Democracia monocromática, em andamento ou em solidificação", quando diz:

Se é que alguém duvidava, os últimos dias têm sido prenhes em deixar ver agendas e desejos que pareciam esquecidos. Mais um 7 de Setembro e também mais do mesmo cardápio. Se alguém tinha dúvida de que as datas comemorativas do Estado haviam sido capturadas e abocanhadas pelo partido no poder, o que foi dito a 7 de Setembro de 2016 nas cerimónias centrais em Pemba, revelam o que vai na alma de muita gente. Ficou claro que todo o palavreado sobre paz, democracia, AGP de Roma e demais acordos que se seguiram foram "cozinhados" decididos naqueles momentos para salvaguarda dos "direitos especiais" de "gente especial". Ceder para manter, ceder para adiar, ceder como recuo estratégico, mas jamais ceder com honestidade e abertura. Não é que a máscara tenha caído, pois isso já aconteceu faz tempo. O que os diversos discursos evidenciaram é que os "camaradas" não mudaram. Têm andado a falar de democracia, mas, para eles, só é democracia quando eles estão no poder, mesmo que isso seja feito e aconteça sem observância dos preceitos democráticos. A 
recuperação de supostos discursos "nacionalistas" mostra que existe um "finca-pé" e irredutibilidade que prenunciam maus tempos para os moçambicanos (NHANTUMBO, 2016, p. 3).

\section{Considerações Finais: Em Aberto}

Se há algo que não podemos e não devemos esquecer é que, todo o caminho, feito após a independência e durante a independência, tem um dono e uma narrativa que se impõem: FRELIMO. A educação para a hegemonia política da FRELIMO não é democrática, partilhável. Porém, o mesmo também poderíamos dizer da RENAMO relativamente a esta sede de poder. $\mathrm{Na}$ minha opinião, não há maturidade política, nem desejo de igualdade em viver e distribuir com justiça o país do Rovuma ao Maputo. Quer a FRELIMO quer a RENAMO querem o mesmo: poder. Mas, na verdade, o que acontece é que quem detém a chave do cofre desse elemento por tantos almejado é a FRELIMO, que não irá, senão sob uma pressão de carácter divino, abrir mão das suas hegemonias e privilégios de longa data. Chamar para o palco das negociações mediadores e outras personalidades na tentativa de atenuar as hostilidades e o ódio entres estes dois partidos, é verdadeiramente um ato de atirar areia para os olhos (TIMÓTEO, 2016). A ser isto verdade, não serão as elites políticas que sofrerão com as consequências desta total imaturidade política. Infelizmente, para isso, sabem essas mesmas elites que temos sempre o povo como um 'saco de boxe' para todos os embates.

Falta calcorrear um longo curso histórico e social de aprendizagem para a democracia, para sabermos dar valor ao que chamamos de igualdade, de respeito e de responsabilidade cívica e governamental. De facto, 41 anos é uma vida pequena, jovem, ainda imberbe para estar preparada para aceitar sem medos e de peito aberto uma nação do Rovuma ao Maputo. Certamente, é preciso decalcar e repartir assiduamente as palavras que o poeta 'cantou' no antigamente da "nação que ainda não existe":

Vim de qualquer parte

de uma Nação que ainda não existe.

Vim e estou aqui!

Não nasci apenas eu

nem tu nem nenhum outro...

mas Irmão.

(CRAVEIRINHA, 1980, p. 18). 


\section{Referências}

CAN, Nazir. Para Além da História. Campo de Trânsito de João Paulo Borges Coelho. In: Revista Via Atlântica, São Paulo, USP, n. 16, p. 105-117, 2009.

CRAVEIRINHA, José. Xigubo. Lisboa: Edições 70, 1980.

GEFFRAY, Christian. La cause des armes au Mozambique: Anthropologie d'une guerre civile. Paris: Editions Kartala, 1990.

IGREJA, Victor. Memories as weapons: The politics of peace and silence in post-civil war Mozambique. In: Journal of Southern African Studies, v. 34, n. 3, p. 539-556, 2008. http://dx.doi.org/10.1080/03057070802259720

KHAN, Sheila. Imigrantes Africanos Moçambicanos. Narrativa de Imigração e de Identidade e Estratégias de Aculturação em Portugal e na Inglaterra. Lisboa: Edições Colibri, 2009.

. Narrativas, rostos e manifestações do pós-colonialismo moçambicano nos romances de João Paulo Borges Coelho. In: Revista Gragoatá, Niterói, n. 24, p. 131-144, 2008.

LABAN, Michel. Moçambique. Encontro com Escritores. Porto: Fundação Eng. António de Almeida, 1998. Vol. III.

MACHEL, Samora. Mensagem ao povo de Moçambique - Tomada de Posse do Governo de Transição em 20 de Setembro de 1974. Porto: Ed. Afrontamento, 1974.

NHANTUMBO, Noé. Democracia monocromática, em andamento ou em solidificação. In: Canalmoz, ano 8, n. 1789, set. 2016. p. 3.

TIMÓTEO, Adelino. O País do Nunca Mais. In: Canalmoz, ano 8, n. 1790, set. 2016. p. 3-4.

\section{Fontes}

CAHEN, Michel. A hegemonia da FRELIMO é uma ameaça à democracia. In: Savana, 10 jun. 2016. p. 15-16.

DIOGO, Luísa. As aldeias comunais eram necessária. In: Savana, 26 ago. 2016. p. 3. REBELO, Jorge. Se a rutura acontecer, que venha. In: Savana, 27 maio 2016. p. 4-5.

VINES, Alex. Como é que Moçambique consegue gerir a crise da dívida? In: Savana, 27 maio 2016. p. 5.

Recebido: 06 de janeiro de 2016 Aprovado: 20 de abril de 2016

\section{Autora/Author:}

SHEILA KHAN <sheilakhan31@gmail.com>

- Investigadora do Centro Interdisciplinar de Ciências Sociais da Universidade do Minho (CICS.NOVA.UMinho). Doutorada em Estudos Étnicos e Culturais pela Universidade de Warwick, Inglaterra. Tem, no seu percurso académico, centrado a sua atenção nos estudos pós-coloniais, com especial enfoque nas relações entre Moçambique e Portugal, incluindo a questão dos imigrantes moçambicanos em Portugal. De entre os temas que tem trabalhado inclui-se a história e a literatura moçambicana e portuguesa contemporâneas, narrativas de vida e de identidade a partir do Sul global, autoridades de memória e de pós-memória. É de destacar o seu recente livro, Portugal a Lápis de Cor: A Sul de uma pós-colonialidade (Almedina, 2015).

- Researcher at the Centro Interdisciplinar de Ciências Sociais da Universidade do Minho (CICS.NOVA.UMinho). PhD in Ethnic and Cultural Studies from the University of Warwick, England. She has, in her academic career, focused her attention on postcolonial studies, with special emphasis on relations between Mozambique and Portugal, including the question of Mozambican migrants in Portugal. Among the themes of research, stand out the Mozambican and Portuguese history and literature, life narratives and identity from the global South, and memory and post-memory authorities. She is the author of Portugal in Colour Pencil: The South of Postcoloniality (Almedina, 2015). 